\title{
EXPERIMENTAL STUDY OF STEAM GENERATION BY PARABOLIC TROUGH CONCENTRATOR WITH TWO AXES TRACKING
}

\section{${ }^{*}$ Yasameen S. Raheema ${ }^{1}$}

Bashar O. Bedaiwi ${ }^{1}$

\begin{abstract}
This paper describes an experimental model for estimating parabolic trough solar collector performance, as the Arduino micro-controller technology was applied to improve the optical and thermal efficiency of the system. The receiving tubes of different internal diameters $(2 \mathrm{~mm}$, $6 \mathrm{~mm}$ ) were implemented to evaluate system performance. The practical investigation of the solar concentrator was conducted to generate steam at moderate temperatures, as the experiments were executed in Baghdad with geographical coordinates $\left(33^{\circ}\right.$ $18^{\prime} \mathrm{N}, 44^{\circ} 21^{\prime} \mathrm{E}$ ) during specific days. The results showed the effectiveness of small diameters, as the significant enhancement of thermal performance was at a flow rate of $8 \mathrm{~L} / \mathrm{h}$ and receiver tube diameters of $2 \mathrm{~mm}$, as the improvement was 30\% compared to $6 \mathrm{~mm}$ tubes.
\end{abstract}

Keywords: Parabolic Trough, Thermal Efficiency, Dual Tracking.

\section{Introduction}

Most developing countries cannot generate electricity, which impedes industrial production and industry development; wherefore, energy consumers and citizens need to invest heavily in spare diesel generators. [1], countries with high solar radiation have a favorable potential in applying solar thermal technologies in energy production, such as Parabolic Trough Collector (PTC) [2]. This technology could be merged with a Dual-Axis tracker type system with two degrees of freedom due to composed of two axes of rotation where these axes are one axis perpendicular to the other. [3]. Many researchers are interested in this field (Chiad et al., 2011) [4] design and construct (PTSC), whereas studying the effect of mirror glass reflector, two-axis tracking system, and synthetic oil as heat transfer fluid on thermal efficiency. The results have found that the thermal efficiency of the PTSC reached up to 45-35\%. (Zhang et al., 2013) [5], Performed enhancement generate direct steam a medium-temperature parabolic trough concentrator, to evaluate the effect of wind conditions and receiver element on overall heat losses in $U$ type double glazing solar absorber. This work found that thermal efficiencies were 0.791 in calm and 0.472 windy conditions, while the efficiencies rose to 0.792 and 0.663 for the same conditions. (Majeed et al., 2014) [6], conducted assessment performance generate electricity by parabolic trough system in Basra city simulation by (EES) software depending on data belong to the Mojave Desert for estimate effect of climate conditions, absorber length. The results have indicated that thermal efficiency in summer months more significant than in winter, and thermal losses are more for long pipes.

The experimental work that has been carried out by (Qu et al., 2017) [7], conducted an improvement in the efficiency of the parabolic

\footnotetext{
*Corresponding Author: ehma002@uomustansiriyah.edu.iq
} 
trough solar concentrator to test the influences of (horizontal-axis and rotatable axis) tracking patterns on the thermal performance of PTC in autumn and summer. The results showed that the rotating tracking technique exceeds the horizontal tracking increase of about $5 \%$ with the daily average efficiency of the PTC, due to the rotation of the collector enables the surface azimuth angle to be changed, which makes the incidence angle small and consequently reduces cosine loss.

(Awad \& Aziz, 2018) [8], developed an improvement in sun tracking system in solar panels, with experimental and theoretical methods using 16f877a-microcontroller and simulated circuit in Sprouts software to evaluate bi-direction sun tracker. It has been found enhancement in system efficiency by $23 \%$ using stepper motor system and under different irradiance cases.

Generation steam in PTC solar concentrator in Kerbala has been investigated (Abbood \& Mohammed, 2019) [9] and utilized the theoretical and practical approach by using a mathematical model of energy balances equations in Matlab software to calculate solar radiation, optical and thermal models to evaluate the effect of working fluids (water, hydraulic oil, and ethylene-glycol based water). The study concluded that improving the collector efficiency using hydraulic oil compared to water was by $31.7 \%$.

Thermal improvement on PTC was conducted by (Jebasingh et al., 2019) [10], utilized both theoretical and experimental methodology to estimate the influence of absorber tube shape on thermal efficiency. The study has concluded that the elliptical receiver increases the efficiency by around $9 \%$ on average, compared to the overall circular shape.

\section{Summary}

It is noted from the research mentioned above that no focus has been placed on improving thermal systems by using small diameters or showing its effect with the application of dual tracking on parabolic trough performance.

The primary objectives of the research are: implementing Arduino technology with DualAxis to improve the optical and thermal performance of the PTC system. Furthermore, horizontal mini diameter tubes are inserted in a non- evacuated circular glass tube to enhance steam generated by the solar concentrator.

\section{Theoretical Approach}

\subsection{Design Parabolic Collector}

The parabola is distinguishing by its general equation that represented by the formula:

$x^{2}=4 f y$

reflector mirror that creates a curve with radius at collector axis and best known as rim angle, which can be described as [11]:

$\varphi_{r}=\tan ^{-1}\left[\frac{8\left(\frac{f}{w}\right)}{16\left(\frac{f}{w}\right)^{2}-1}\right]$

The aperture is a vital parameter term associated with the rim angle, therefore, and it can be express as [12]:

$w_{a}=4 \tan \left(\frac{\varphi_{r}}{2}\right)$

Also, the radius of parabolic as symbolized:

$r=\frac{2 f}{1+\cos \left(\varphi_{r}\right)}$

Another important term is the concentration ratio, which is defined as a division of area aperture over the area of the absorber, and it can be written as [11]:

$C=\frac{A_{a}}{A_{a b s}}$

Where for tubular absorber:

$A_{a}=\mathrm{w} * \mathrm{~L}$ and; $A_{a b s}=\pi * D_{o} * L$ 
Moreover, there is a parameter for determining the length of reflector surface curvature, which is given by [12]:

$$
\begin{aligned}
& S=\frac{H p}{2}\left[\sec \left(\frac{\varphi_{r}}{2}\right) \tan \left(\frac{\varphi_{r}}{2}\right)+\ln \left\langle\sec \left(\frac{\varphi_{r}}{2}\right)+\right.\right. \\
& \left.\left.\tan \left(\frac{\varphi_{r}}{2}\right)\right\rangle\right]
\end{aligned}
$$

\subsection{Thermal Calculation}

The thermal efficiency can be estimated by:

$\eta_{t h}=\frac{Q_{u}}{Q_{s}}$

Where the beneficial solar irradiation $Q_{s}$ defined as the solar irradiation energy on the aperture of the parabolic trough is written as:

$Q_{s}=A_{a} * G_{b}$

While useful solar heat $Q_{u}$ which can be found in form; by applying energy balance[13];

$Q_{u}=\dot{m} c_{p}\left(T_{\text {out }}-T_{\text {in }}\right)$

Also, beneficial heat gains at the boiling zone can describe as:

$Q_{\text {evp }}=x * \dot{m} * h_{f g}$

\section{Experimental Work}

\subsection{Parabolic Trough Assembly}

The parabolic trough collector system comprises two troughs with a total area of $(2 \mathrm{~m} \times 2 \mathrm{~m}$ aperture) and an effective area $(0.976 \mathrm{~m} \times 1.94 \mathrm{~m})$ for each trough. The PTSC is mainly composed of three parts: reflector, solar tracking mechanism, and absorber tubes.

\subsubsection{The Reflector}

The reflector was designing from a rectangular polished stainless steel (304) sheet, with dimensions $(2 \mathrm{~m} \times 1.12 \mathrm{~m} \times 0.005 \mathrm{~m})$ to be in the form of a parabola depending on the rim angle to determine focus point as shown in Figure 1.

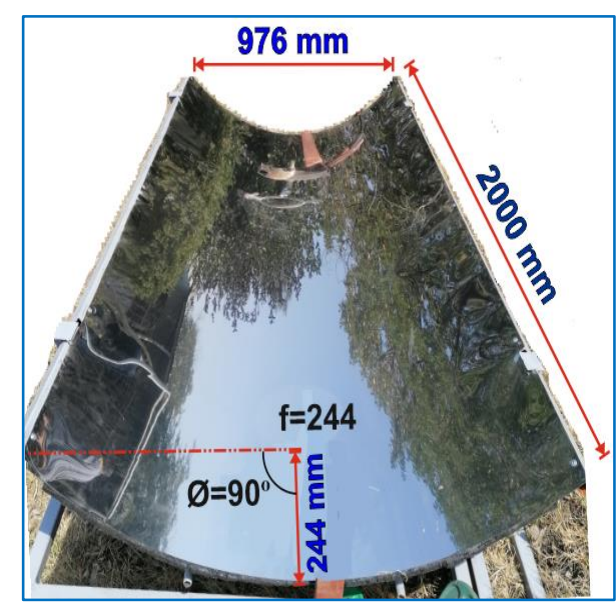

Figure 1. Reflector Design

The back of the reflector is insulated to reduce heat losses by convection, as shown in Figure below.

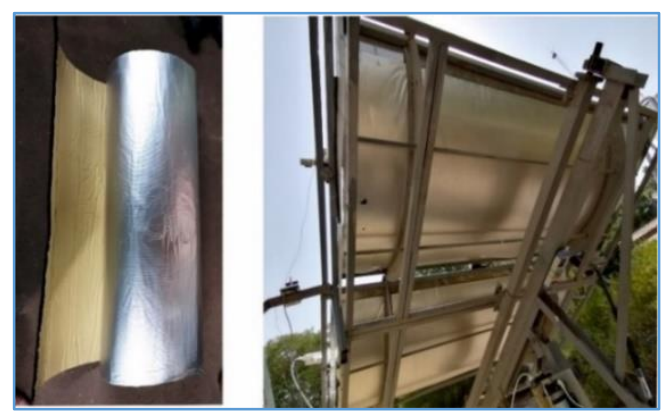

Figure 2. Thermal Insulation in the rear of Reflector

In addition, there is the supporting structure, and it consists of the fixed part on which the collector rests during difficult weather conditions and high stress due to operation. It has a heavy circular base of iron surrounded by four rectangular arms fixed with nails to the ground on one side and linked on the other side by a hinge axis to a rectangular shaft that determines the movement in one direction, north-south, for action in an east-west another rotor shaft has been installing on a single beam to control motion, as shown in Figure 3. 


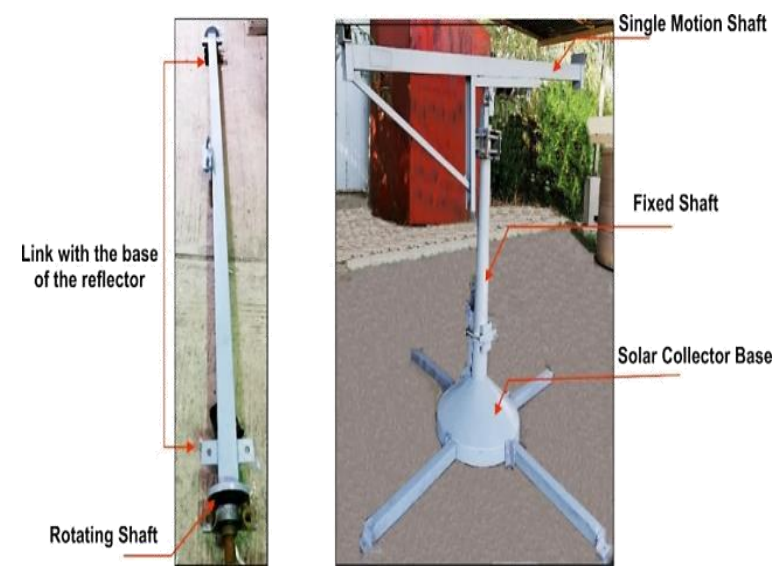

Figure 3. Mechanical Parts of the Assembly Structure

\subsection{Solar Tracking Components}

\subsubsection{Micro-Controller}

In this experiment, Arduino Uno R3 is connected to LDRs by converting an analog signal into a readable digital value.

\subsubsection{LDR sensors}

Carbon film resistors have been attached with Arduino to provide sensors with electrical signals and ground pins. In cross design, four photoresists are placed around the base in a square shape according to the four directions.

\subsubsection{Electric Actuators / DC Motors}

Two motors were used; one motor was used for the east-west movement and the other northsouth.

\subsubsection{Relays}

After determining the operating voltage of the actuators, the relays are selected of 24 volts and using an $\mathrm{AC} / \mathrm{DC}$ converter of the same voltage after examining the electrical components inside the laboratory and conducting the necessary simulations for programming the Arduino; see Figure 4.

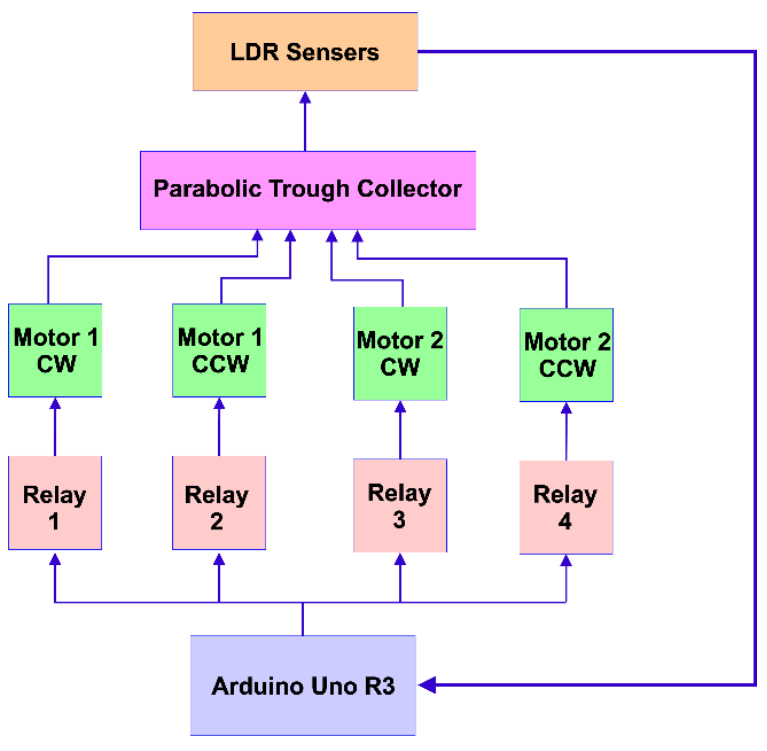

Figure 4. Working principle of the actuators in the tracking system

The parts were assembled and connected with the parabolic trough system as shown in following Figure 5.

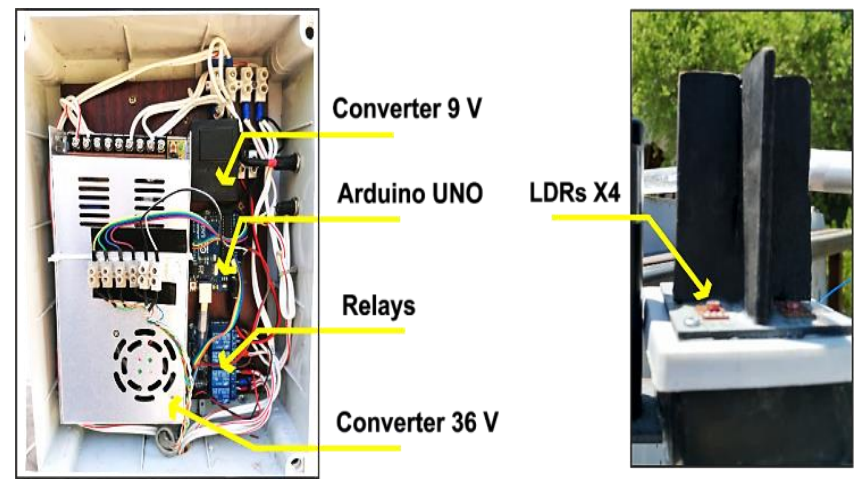

Figure 5. Electrical tracking circuit components

\subsection{Absorber Tubes}

The copper tubes available in the local market were selected with specifications as shown in Table 1.

Table 1. PTC Specification Models Dimensions

\begin{tabular}{lcl}
\hline Description & Symbol & Value \\
\hline Collector aperture area & $A_{a}$ & $1.89344 \mathrm{~m}^{2}$ \\
Parabolic aperture width & $w_{a}$ & $0.976 \mathrm{~m}$ \\
Parabolic trough length & $L c$ & $2 \mathrm{~m}$ \\
Focus point & $f$ & $0.244 \mathrm{~m}$
\end{tabular}


Table 1. PTC Specification Models Dimensions

\begin{tabular}{lcl}
\hline Description & Symbol & Value \\
\hline Inner diameter receiver & $D_{r i}$ & $(2,6) \times 10^{-3} \mathrm{~m}$ \\
Outer diameter receiver & $D_{r o}$ & $(4,7) \times 10^{-3} \mathrm{~m}$ \\
Absorber surface area & $A_{s}$ & $(0.124,0.217) \mathrm{m}^{2}$ \\
Concentration ratio & $C$ & $25.9,14.8$ \\
Inner diameter glass & $D_{c i}$ & $0.34 \mathrm{~m}$ \\
Outer diameter glass & $D_{c o}$ & $0.36 \mathrm{~m}$ \\
No. of models & & 2 \\
Rim angle & $\varphi_{r}$ & $90^{\circ}$ \\
Absorber length & $L$ & $(11.64,3.88) \mathrm{m}$ \\
Optical efficiency & & 0.53 \\
\hline
\end{tabular}

A 4-inch copper tube welded as an entrance to collect the water before passing through the tested tubes at the beginning and end of each stage to connect the corresponding water plugs. In addition, four pieces of Teflon, $10 \mathrm{~cm}$ long, were cut as anchors for the glass cover to be fixed on the stands, then receiver tubes inserted in a non- evacuated Pyrex glass envelope, as presented in Figures (6 and 7).

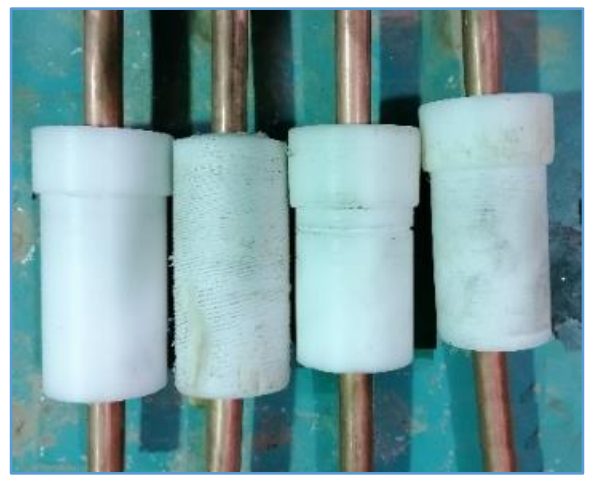

Figure 6. Glass Envelope Anchors

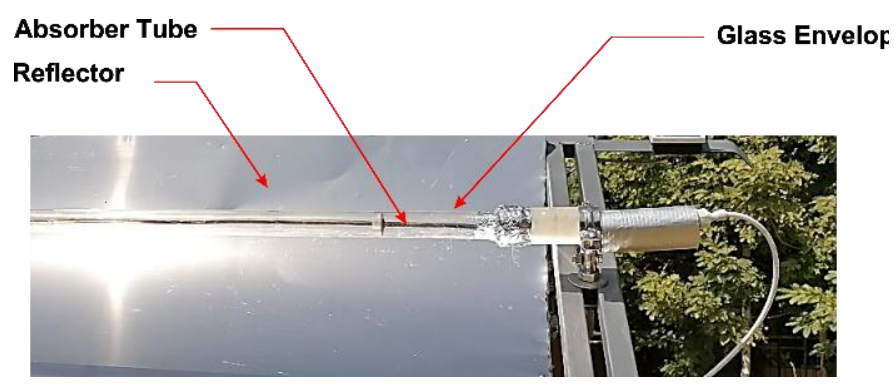

Figure 7. Heat Elements Collection
The PTC concentrates solar radiation through a parabolic reflecting mirror, where the sun's rays fall on the collector and focus in the form of a focal line, where the absorption tube fixes that line, whereby HTF flows through the pipes and gradually acquires heat, so two models of absorber tubes were tested as follows:

\subsubsection{Case (1): Tube in Zigzag Form}

In this case, the tube was analyzed with an inner diameter of $2 \mathrm{~mm}$ and $5820 \mathrm{~mm}$ total length for each stage, as shown in Figure 8.

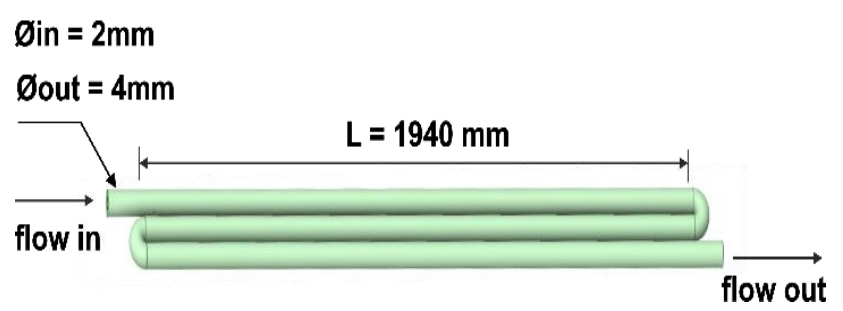

Figure 8. Tubes in Zigzag Shape

\subsubsection{Case (2): Tube in Conventional Form}

For the second case has been adopted inner tubes diameter where equally for total inner diameter with the previous model, $6 \mathrm{~mm}$ inner diameter along $3880 \mathrm{~mm}$ for two stages, as shown in Figure 9:

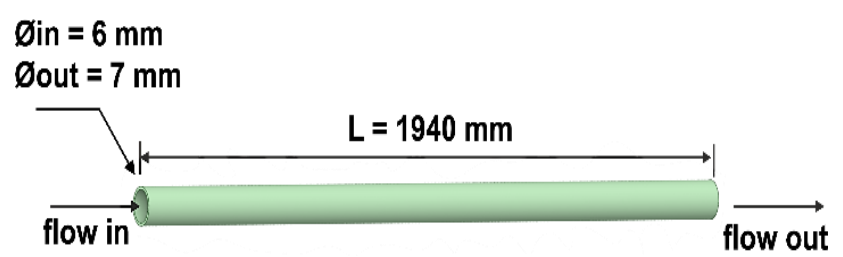

Figure 9. Tubes in Conventional Shape

\subsection{The Procedure of Experimental Work}

The experiment has been testing on sunny days in the Ministry of Youth and Sports/ Baghdad/ Al-Zawra site with geographical coordinates: Latitude $\left(33.33{ }^{\circ} \mathrm{N}\right)$, Longitude $\left(44.39^{\circ} \mathrm{E}\right)$, by taking solar radiation for hours between (9 AM2 PM) in two consecutive days and two flow rates feeds respectively, which are constant at values 
(8 and10) $\mathrm{L} / \mathrm{h}$ of tap water have been used as illustrated in Tables (2 and 3) and Figure 10:

Table 2. Cases Study Data

\begin{tabular}{|c|c|c|c|c|}
\hline $\begin{array}{l}\text { Case } \\
\text { No. }\end{array}$ & $\begin{array}{c}\text { Din } \\
(\mathbf{m m})\end{array}$ & $\begin{array}{c}\text { Length } \\
\text { (m) }\end{array}$ & $\begin{array}{c}\text { Flow Rate } \\
\text { L/h }\end{array}$ & Day tests \\
\hline $1^{\text {st }}$ & 2 & 11.64 & 8,10 & $\begin{array}{c}15,16 \\
\text { Sept. } 2020\end{array}$ \\
\hline $2^{\text {nd }}$ & 6 & 3.88 & 8,10 & $\begin{array}{c}19,20 \\
\text { Sept. } 2020\end{array}$ \\
\hline
\end{tabular}

Table 3. Solar irradiation recording at cases study

\begin{tabular}{ccc}
\hline Time (hr) & 15 Sept. W/m & 19 Sept. W/m \\
\hline 9 & 605 & 589 \\
10 & 649 & 634 \\
11 & 689 & 672 \\
12 & 703 & 694 \\
1 & 681 & 665 \\
2 & 644 & 621 \\
\hline
\end{tabular}

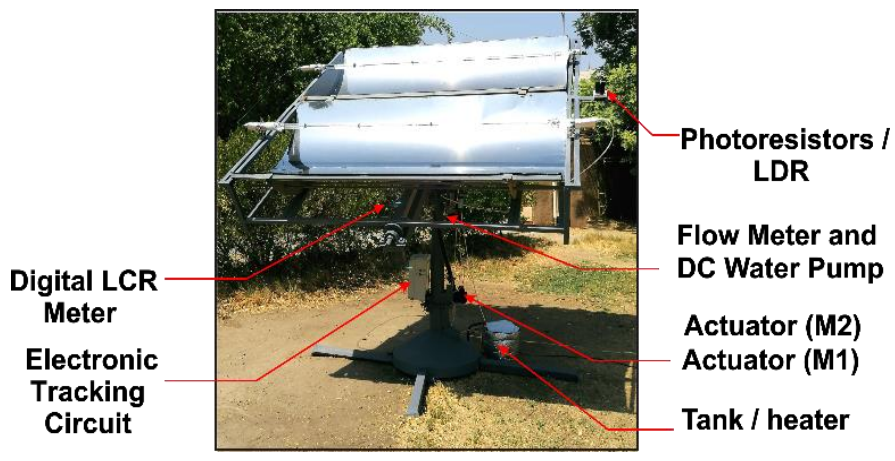

Figure 10. Rig of Parabolic Trough Collector

The fluid enters the solar collector through a tank with a water temperature of $70^{\circ} \mathrm{C}$ to pass through the first and second stages respectively where is circulated in an open cycle, five temperature sensors type $\mathrm{K}$ are distributed as in Figure 11, Whereas (T1, T3, and T5) measured fluid temperatures while (T2, T4) record absorber surface.

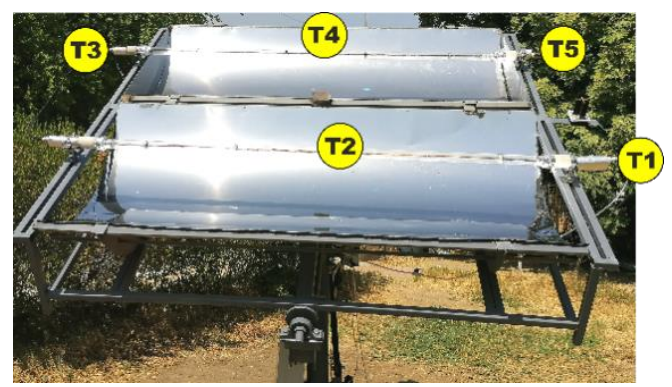

Figure 11. Distribution Temperatures Indicators

The experimental device was designed, built, and tested to verify its ability to produce steam at moderate temperatures.

\section{Results and Discussion}

This study clarifies the experimental approach to achieved generate steam by using a concentrator of parabolic trough PTC system with two axes tracking to estimate different parameters that influence the thermal system such as mass flow rate variation and reduction effect of the inner diameter of absorber tubes.

\subsection{Outlet Temperature}

The practical readings of the exit steam temperature of the collector by means the readings of the thermal sensors which installed and distributed on the collector, Figure (12) illustrated the second model with a slight increase in the outlet temperature of the steam, as the maximum temperature reached $97.6^{\circ} \mathrm{C}$ compared to the first model $96.9{ }^{\circ} \mathrm{C}$ and this indicates that temperature has been stable because the exit steam is in saturation condition, despite the difference in the amount of vapor generated for the two models.

\subsection{Vapor Quality}

After recording the readings of the thermal sensors T2 and T4 installed on the surface of the receiver and imposing the temperature of the glass as a function of the ambient temperature By assuming $T_{g}$ as demonstrated in [14]; the heat loss coefficient was set, and according to the 
calculations of the loss coefficient as illustrated in [15], Figure (13) demonstrate the losses for the first model amounted to $39 \mathrm{~W} /\left(\mathrm{m}^{2} . \mathrm{K}\right)$, while the second model reached $33 \mathrm{~W} /\left(\mathrm{m}^{2} . \mathrm{K}\right)$, due to the increase in the surface area of the receiver tube in the first model. However, it is more vapor volume compared to the first model, by a difference of $30 \%$ and $34 \%$ at a flow rate of $(8$, 10) $\mathrm{L} / \mathrm{h}$, respectively.

In these cases, the practically measured data were recorded for two consecutive days of the same conditions as shown in Table 1; all the necessary data were recorded to study the performance of the solar collector, such as (wind speed and $\left.T_{a m b}\right)$.

Figure (14) illustrates the quantities of steam generated for the first model and two feeding rates, as the lower the flow rate, the higher the amount of steam quality during daylight hours, as the amount of steam begins to gradually increase until it reaches a peak at the peak of solar radiation at $12 \mathrm{PM}$, then begins to decline with the decrease in the levels of solar radiation as the steam quality reaches $(52 \%$ and $41 \%)$, respectively at a flow rate of (8 and 10) $\mathrm{L} / \mathrm{h}$. While the values of steam quality decreased in the second model, as shown in Figure (15), as it reached a maximum value (38\% and $27 \%$ ) for the two test flow rates, respectively. The difference between the two models indicates an average of $27 \%$ when producing steam, suggesting that smaller diameters provide a larger contact area with the fluid, which heats it faster.

\subsection{Useful Heat Gain}

The beneficial energy was evaluated by calculating steam quality at the end of the two stages. The flow rate, in addition to the latent heat of vaporization of water at the exit temperature, as Figures (16) shows the practically beneficial energy at the flow rates of $(8,10) \mathrm{L} / \mathrm{h}$, an improvement in the useful thermal energy between the first and second models for a flow rate of $8 \mathrm{~L} / \mathrm{h}$ reached $77 \%$, as the maximum gain reached $3568 \mathrm{~W}$ at the time of peak solar radiation.

In contrast, Figure (17) shows it got the second model, $815 \mathrm{~W}$, and the results also showed an increase of $19 \%$ for the flow rate of $10 \mathrm{~L} / \mathrm{h}$ for two tube models compared to a flow rate of $8 \mathrm{~L} / \mathrm{h}$. Due to the high amount of steam leaving the collector, as the water absorbs heat energy from solar radiation and has essentially potential energy, therefore; vapor will have higher potential energy and thus raise the energy obtained from the collector.

\subsection{Thermal Efficiency}

The measured thermal efficiency is influenced by the process results for the beneficial energy and the aperture of PTC, while the radiation level does not affect this test because the change occurs with a slight difference of $1 \%$.

To analyze the performance of the PTSC, Figure (18) illustrates a comparison between the thermal efficiency of the variety of flow rates. The maximum difference in thermal efficiency was $44.6 \%$ for a flow rate of $8 \mathrm{~L} / \mathrm{h}$, with a slight difference of about $3 \%$ for a flow rate of $10 \mathrm{~L} / \mathrm{h}$. Meanwhile, Figure (19) of the second model showed a decline in the values of the practical thermal efficiency of the solar system to reach $29.7 \%$ at the peak level of radiation, with an insignificant difference of $9 \%$ from the flow rate of $10 \mathrm{~L} / \mathrm{h}$, the first model gives the highest measured thermal efficiency compared to the second model, an increase of $33 \%$. The reason is to increase vapor quality and thus increase the amount of beneficial energy that directly increases the efficiency despite the heat losses. 


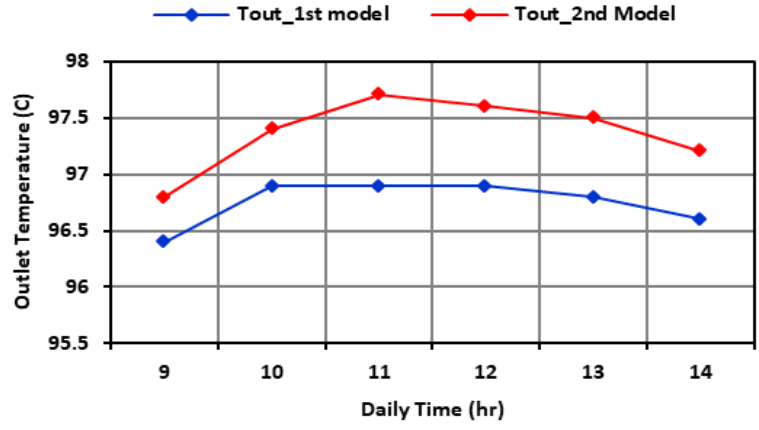

Figure 12. Exit Temperatures for two model of absorber

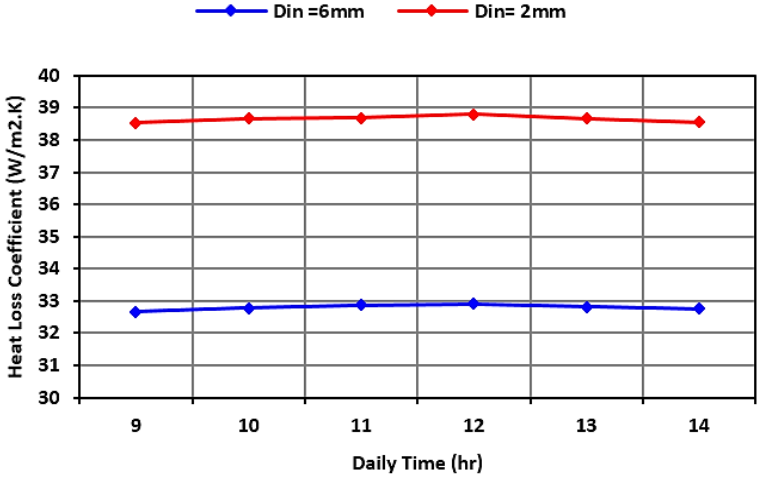

Figure 13. Comparison of heat losses for a receiver of different diameters during the test time

$\longrightarrow$ 8L/h $\longrightarrow 10 \mathrm{~L} / \mathrm{h}$

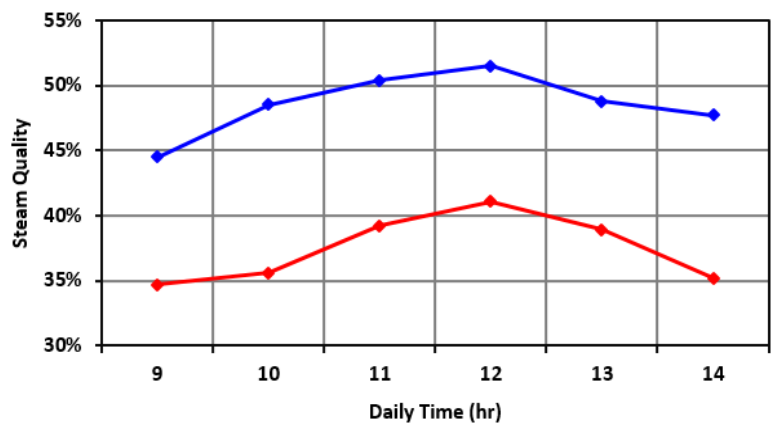

Figure 14. Vapor Quality in absorber tube Din $=2 \mathrm{~mm}$ with hours of radiation

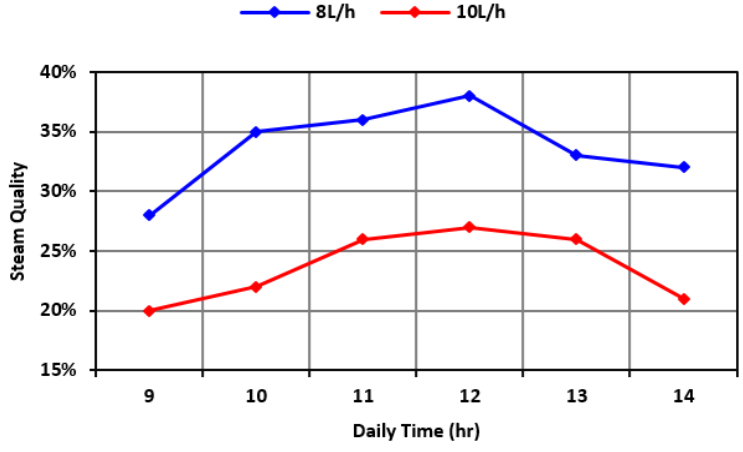

Figure 15. Vapor Quality in absorber tube Din $=6 \mathrm{~mm}$ with hours of radiation

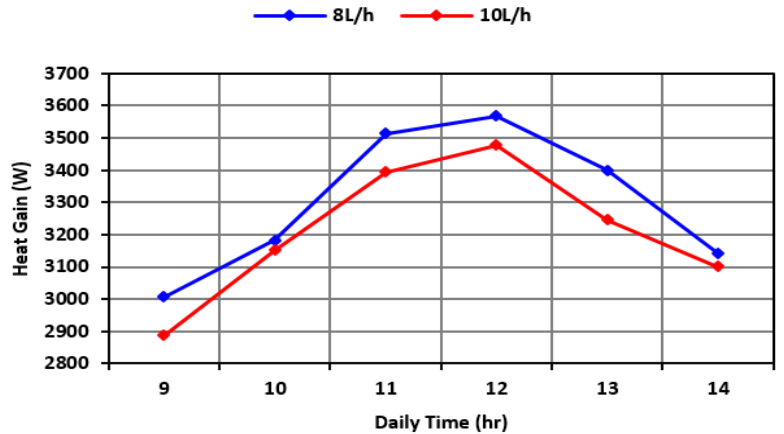

Figure 16. Practical Heat Gain of absorber tube Din $=2$ $\mathrm{mm}$ with hours of radiation

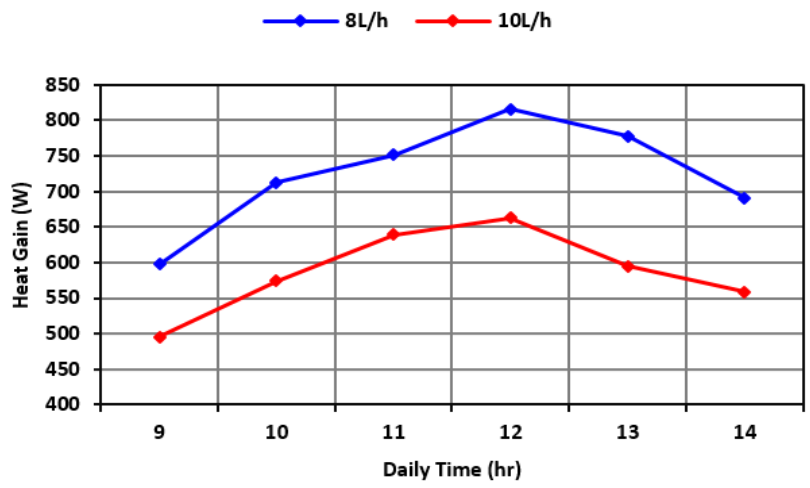

Figure 17. Beneficial Heat Gain of tube Din $=6 \mathrm{~mm}$

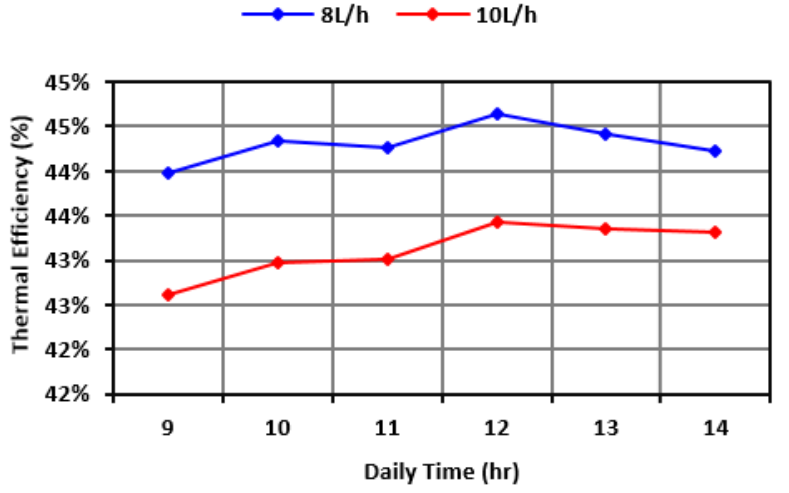

Figure 18. The efficiency of absorber tube Din $=2 \mathrm{~mm}$ with hours of radiation

$\multimap 8 \mathrm{~L} / \mathrm{h} \longrightarrow 10 \mathrm{~L} / \mathrm{h}$

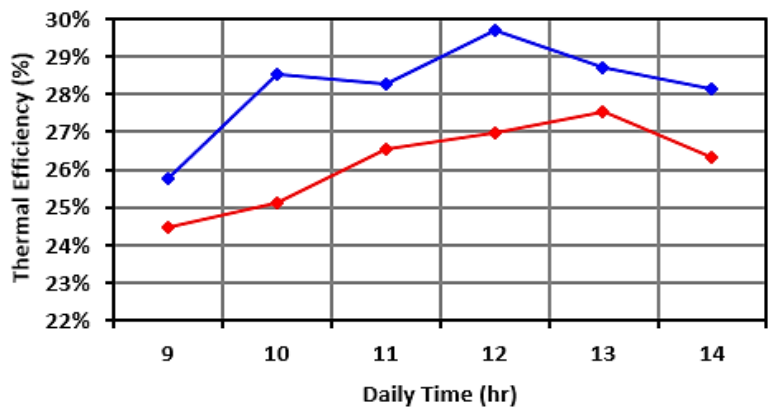

Figure 19. The efficiency of absorber tube Din $=6 \mathrm{~mm}$ with hours of radiation 


\section{Conclusions}

The PTC system was designed to take into account the fundamental parameters in building the solar model. It was practically investigated to analyze the thermal performance of steam generation at moderate temperatures and integrate a microcontroller system for dual tracking of solar radiation to improve the optical and thermal efficiency of the system.

In this study, experimentally tests were performed for receiving tubes of internal diameters ( $2 \mathrm{~mm}$ and $6 \mathrm{~mm}$ ) with an increase in the length of the first model to equal the second model when exposed to the concentration of solar radiation in focus and for water feeding rates $(8$ and 10) $\mathrm{L} / \mathrm{h}$.

The results have been found that the best improvement in thermal efficiency approached were $44.6 \%$ and $29.7 \%$ for the first and second models, with the generation of steam quality about (52\% and $38 \%$ ), respectively, at a flow rate of $8 \mathrm{~L} / \mathrm{h}$.

\section{Acknowledgments}

We express our appreciation to the Ministry of Youth and Sports/ Scientific Care Department for supporting this research.

\section{Conflict of Interest}

The authors confirm that the publication of this article causes no conflict of interest.

\section{Abbreviation}

$\begin{array}{ll}\text { PTC } & \text { Parabolic Trough Collector } \\ \text { PTSC } & \text { Parabolic Trough Solar Collector } \\ \text { EES } & \text { Engineering Equation Solver } \\ \text { LDR } & \text { Light Dependent Resistor } \\ A_{a} & \text { Aperture Area, } \mathrm{m}^{2} \\ A_{a b s} & \text { Area Absorber, } \mathrm{m}^{2} \\ G_{b} & \text { Normal Direct Beam, } \mathrm{w} / \mathrm{m}^{2} \\ x & \text { Vapor Quality } \\ \dot{m} & \text { Mass Flow Rate, } \mathrm{kg} / \mathrm{s}\end{array}$

$c_{p} \quad$ Specific Heat Capacity J/kg. $\mathrm{k}$

$h_{f g} \quad$ Latent Heat of Evaporation J/kg. $k$

$T_{\text {out }} \quad$ Outlet Temperature, ${ }^{\circ} \mathrm{C}$

$T_{\text {out }} \quad$ Inlet Temperature, ${ }^{\circ} \mathrm{C}$

$Q_{u} \quad$ Useful heat gain $W$

$Q_{s} \quad$ Energy solar radiation arrived to PTC

$W \quad$ aperture of collector, $\mathrm{m}$

C concentration ratio

$\mathrm{S}$ reflector surface curvature

$f \quad$ focal length

$T_{g} \quad$ glass cover temperature, ${ }^{\circ} \mathrm{C}$

$T_{a m b}$ Ambient Temperature, ${ }^{\circ} \mathrm{C}$

\section{Greek Symbols}

$\begin{array}{ll}\eta_{t h} & \text { Thermal Efficiency } \\ \eta_{\text {opt }} & \text { Optical Efficiency } \\ \varphi_{\mathrm{r}} & \text { Rim Angle }\end{array}$

\section{References}

1. DFIC, Cogeneration \& Trigeneration -How to Produce Energy Efficiently. 2016.

2. M. Brooks, I. Mills, and T. Harms, "Design, construction and testing of a parabolic trough solar collector for a developingcountry application," Proc. Sol. World Congr. 2005 Bringing Water to World, Incl. Proc. 34th ASES Annu. Conf. Proc. 30th Natl. Passiv. Sol. Conf., vol. 2, no. January, pp. 849-854, 2005.

3. M. M. Fouad, L. A. Shihata, and E. S. I. Morgan, "An integrated review of factors influencing the performance of photovoltaic panels," Renew. Sustain. Energy Rev., vol. 80, no. May, pp. 1499-1511, 2017.

4. B. T. Chiad, N. K.Kasim, F. A. . Mutlak, A. E. Owaid, R. A. Ahmed, and S. S. Abd, "Parabolic Trough Solar Collector-Design, Construction and Testing," Baghdad Sci. J., vol. 8, no. 2, pp. 658-665, 2011.

5. L. Zhang et al., "An experimental investigation of the heat losses of a U-type solar heat pipe receiver of a parabolic trough collector-based natural circulation 
steam generation system,"

Elsevier,Renewable Energy, vol. 57, pp. 262-268, 2013.

6. A. J. Majeed, S. E. Najim, and S. H. Hammadi, "Simulation Solar Electrical Generation Power Plant By Using Parabolic Trough In Basra City," AlQadisiya J. Eng. Sci., vol. 7, no. 1, pp. 1-11, 2014.

7. W. Qu, R. Wang, H. Hong, J. Sun, and H. Jin, "Prototype Testing of a 300kW th Solar Parabolic-trough Collector Using Rotatable Axis Tracking," Energy Procedia, vol. 105, pp. 780-786, 2017, doi: 10.1016/j.egypro.2017.03.389.

8. H. Awad and S. A. Aziz, "Development and control of a sun tracking system based on stepper motor and $16 f 877 a$ microcontroller," IEEE, 2017 19th Int. Middle-East Power Syst. Conf. MEPCON 2017 - Proc., vol. 2018-Febru, no. December, pp. 347-352, 2018, doi: 10.1109/MEPCON.2017.8301204.

9. M. H. Abbood and M. M. Mohammed, "Experimental and Theoretical
Investigation to Generate Steam by Parabolic Trough Solar Collector with Using Different Heat Transfer Fluids," Int. J. Mech. Mechatronics Eng. IJMME-IJENS, vol. 18, no. 6, pp. 11-22, 2019.

10. V. K. Jebasingh, J. Divya Johns, and T. Arunkumar, "Assessment of circular and elliptical absorber tube in solar parabolic trough collector," Int. J. Ambient Energy, vol. 0, no. 0, pp. 1-12, 2019.

11. J. A. Duffie and W. A. Beckman, Wiley: Solar Engineering of Thermal Processes, 4th Edition - John A. Duffie, William A. Beckman. John Wiley \& Sons, 2013.

12. S. A. Kalogirou, Solar Energy Engineering Processes and Systems, Second. Elsevier, 2014.

13. E. Bellos and C. Tzivanidis, "Enhancing the performance of evacuated and nonevacuated parabolic trough collectors using twisted tape inserts, perforated plate inserts and internally finned absorber," Energies, vol. 11, no. 5, 2018. 